\title{
Cardiac sarcoma diagnosed with EUS-FNB $\square$
}

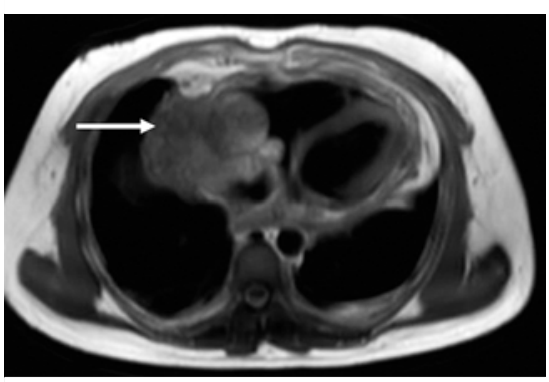

- Fig. 1 T1-weighted four-chamber view of a large, bulky, infiltrative mass in the right atrium (arrow). The signal intensity of the mass is similar to the myocardium.

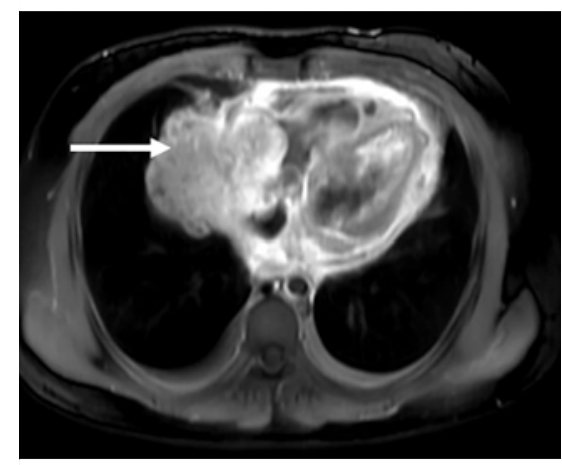

> Fig. 2 Post-contrast axial perfusion images (SPIR) show significant enhancement of the mass with thick and nodular enhancing pericardium due to malignant involvement.

Primary cardiac tumors are rare. Establishing histological diagnosis is technically challenging. We report on performing transesophageal endoscopic ultrasoundguided fine-needle biopsy (EUS-FNB) for a cardiac mass [1-4]. EUS offers advantages of real-time, image-guided targeting of lesions and use of Pro core biopsy needles, which improves tissue yield while avoiding fluoroscopy.

A 26-year-old male presented to a cardiology clinic with recent-onset puffiness of face and shortness of breath that was suggestive of SVC syndrome for 4 weeks duration. Cardiac magnetic resonance imaging showed a large, bulky, infiltrative mass in the right atrium with pericardial extension ( $\mathbf{F i g . 1}$ ). The mass

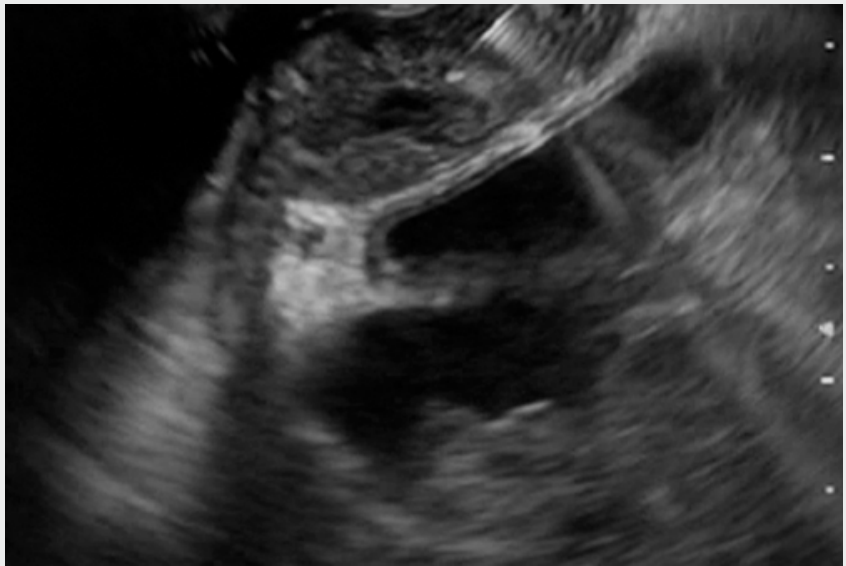

Video 1 Video of linear EUS of the esophagus showing a mass in right atrium extending and causing nodular thickening of pericardium from which a core biopsy was obtained with FNB.

Pericardial thickening, tracing IVC to heart, nodule in pericardium, large mass in right atrium, left heart chambers normal, mass extending into pericardium and along mediastinum, core biopsy from thickened pericardium.

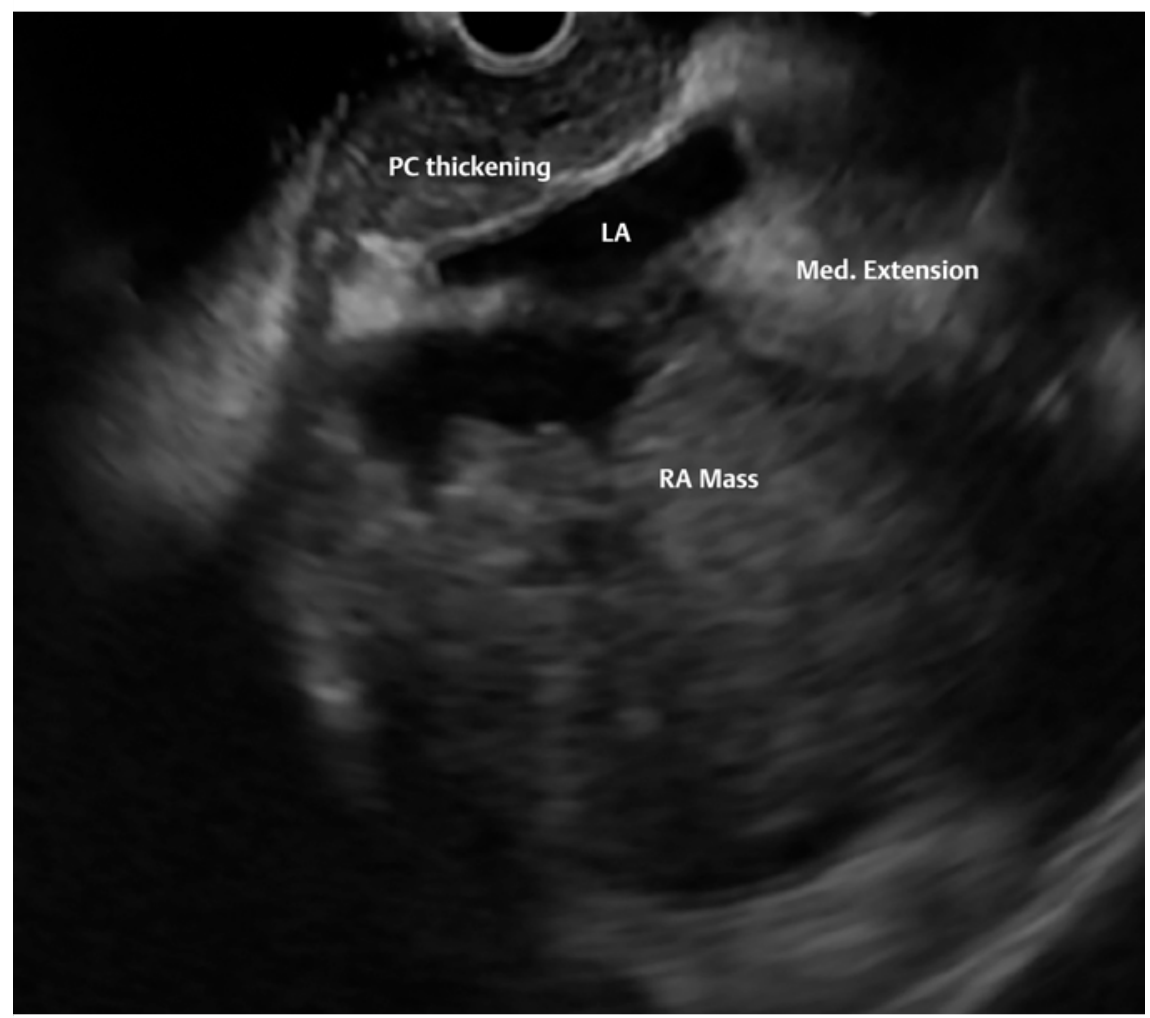

- Fig. 3 Hematoxylin and eosin $20 \times$ shows spindle cells with mild anisonucleosis and hemorrhagic background. 


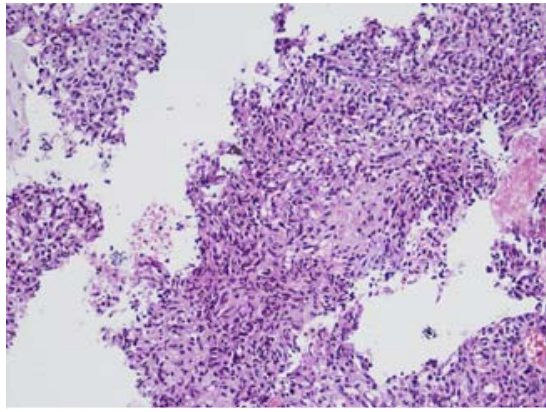

- Fig. 4 Immunohistochemistry $20 \times$. FLI-1 shows strong nuclear positivity.

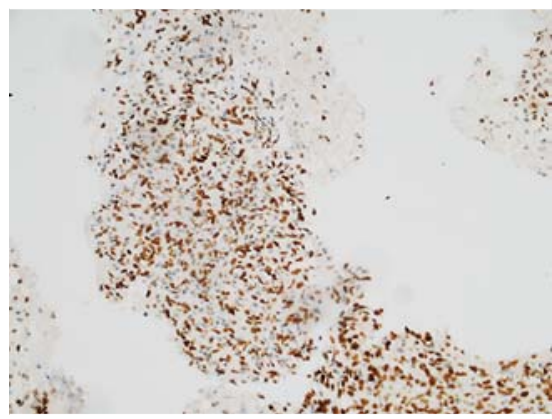

- Fig. 5 Linear mediastinal endoscopic ultrasound image showing a right atrial mass extending into the mediastinum, causing pericardial thickening.

had intense post-contrast enhancement ( Fig. 2).

Linear EUS, performed under supervised deep sedation with intravenous propofol, showed a large mass $(8 \times 8 \mathrm{~cm})$ within the right atrium along with diffusely thickened pericardium in the inferior and posterior aspect along with patchy, large, hypoechoic nodules ( Video $\mathbf{1}$ ). The mass had superior extension around the aortic arch. The left heart chambers
(LA, LV) were normal. EUS- FNB was performed using a 25G core needle (Acquire, Boston Scientific Co, Massachusetts, United States) from the posterior pericardium ( $\mathbf{F i g . 3}$ ). Two passes were made. Rapid onsite cytological evaluation revealed spindle cells. Histology suggested angiosarcoma, which was confirmed with positive immunohistochemistry (IHC) markers (Vimetin, CD31 and 34, FLI-1) (> Fig.4 and > Fig. 5), leading to the final diagnosis of cardiac angiosarcoma. There were no periprocedural adverse events. The oncologist suggested chemotherapy.

The proximity of the esophagus to the heart allows a window for EUS-guided tissue acquisition from the pericardium. We preferred EUS- FNB and not fine-needle aspiration to obtain core tissue for a definitive histological diagnosis along with IHC, which assists in making appropriate clinical decisions. EUS- FNB is minimally invasive and safer for pericardial biopsy in such a clinical scenario than an intravascular approach.

\section{Competing interests}

The authors declare that they have no conflict of interest.

\section{The authors}

Azimudin Haja, Sundeep Lakhtakia, Anuradha Sekaran, Prasad Reddy, Sonam Shah, Aniruddha Pratap, Nageshwar Reddy

Asian Institute of Gastroenterology, Hyderabad, India
Corresponding author

\section{Azimudin Haja}

Asian Institute of Gastroenterology Gastroenterology, AIG Hospitals, Mindspace Road, Gachibowli Hyderabad 500082, India Fax: +1-040-23324255

azimudinhaja@gmail.com

azimudinhaja@yahoo.co.in

\section{References}

[1] Gornals JB, de la Hera M, de Albert M et al. EUS cardiac puncture-guided right atrial tumor. Gastrointest Endosc 2015; 82: 165

[2] Romero-Castro R, Rios-Martin JJ, de Vinuesa PG et al. Pericardial tumor diagnosed by EUS-guided FNA (with video). Gastrointest Endosc 2009; 69: 562-563

[3] Somani P, Sharma M, Patil A et al. Endoscopic ultrasound-guided fine needle aspiration of a pericardial mass. Endoscopy 2016; 48: E45-E46

[4] Romero-Castro R, Rios-Martin JJ, JimenezGarcia VA et al. EUS-FNA of 2 right atrial masses. VideoGIE 2019; 4: 323-324

\section{Bibliography}

Endoscopy International Open 2021; 09: E152E153

DOI 10.1055/a-1268-7675

ISSN 2364-3722

(c) 2021. The Author(s).

This is an open access article published by Thieme under the terms of the Creative Commons Attribution-NonDerivativeNonCommercial License, permitting copying and reproduction so long as the original work is given appropriate credit. Contents may not be used for commecial purposes, or adapted, remixed, transformed or built upon. (https:// creativecommons.org/licenses/by-nc-nd/4.0/) Georg Thieme Verlag KG, Rüdigerstraße 14, 70469 Stuttgart, Germany

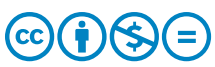

